\title{
Return to Play after Anterior Cruciate Ligament Reconstruction among Amateur Soccer Players
}

\section{Volver a jugar después del ligamento cruzado anterior reconstrucción entre futbolistas aficionados}

\author{
Julián Alonso ${ }^{10}$ Samuel Malig ${ }^{1}$ Cristián Fontboté ${ }^{1}$ Camilo Azar $^{1}$ Francisco Vergara10 \\ Roberto Yáñez ${ }^{1}$ \\ ${ }^{1}$ Clínica MEDS, Santiago, Chile \\ Rev Chil Ortop Traumatol 2019;60:35-38. \\ Address for correspondence Julián Alonso de Frutos, MD, Clínica \\ MEDS, Isabel La Católica 3740, Las Condes, Santiago, Chile \\ (e-mail: jalonso5@gmail.com).
}

\begin{abstract}
Objective The aim of the present study is to assess the return to play among amateur soccer league players after anterior cruciate ligament $(\mathrm{ACL})$ reconstruction.

Materials and Method The surgical protocols of $A C L$ reconstruction surgeries performed in a sports medicine clinic from July $1^{\text {st }}, 2013$, to June $30^{\text {th }}, 2014$, were included in the study. Only the charts of amateur soccer league players who played once or twice a week were selected. The follow-up time was calculated as the number of months between surgery and the telephone survey. At the follow-up, the current status of the soccer playing was recorded. Those patients who were no longer playing in a team were asked what kind of sport they were currently practicing, as well as the main reason for not returning to team playing.

Results A total of 61 (25.6\%) patients met the inclusion criteria. The mean follow-up time was of $22.4 \pm 3.4$ months. At the follow-up, 30 (49.1\%) patients were playing in amateur soccer teams. Among the patients who were no longer playing in a team, 19

Keywords

- anterior ligament cruciate reconstruction

- return to sports

- return to play

- soccer (61.2\%) were playing soccer occasionally, 11 (35.4\%) were practicing other sports, and 1 developed a sedentary life style. The reasons for not returning to team playing were: fear of reinjury in $26 \%$; knee symptoms in $26 \%$; lack of confidence in the knee in $23 \%$, family or job commitments in $23 \%$; and not being eligible to participate in competitive sports in $2 \%$.

Conclusion After an average of two years of $A C L$ reconstruction, only half of the amateur soccer league players return to play.
\end{abstract}

\section{Introduction}

Soccer is the most popular sport worldwide, with an estimated 270 million active players. ${ }^{1}$ Anterior cruciate ligament (ACL) tears are one of the most common knee ligament injuries in athletes, especially in contact sports. ${ }^{2}$ Studies on the non-surgical treatment of ACL injuries have described acceptable functional results, but withdrawal from contact

received

September 29, 2018

accepted

June 12, 2019
DOI https://doi.org/

10.1055/s-0039-1695017. ISSN 0716-4548. sports like soccer is usually required. ${ }^{3,4}$ The desire of the athletes to return to sports is cited as a major indication for ACL reconstruction surgery. ${ }^{5}$ The surgery is performed with the aim of maximizing the stability and functional capacity of the ACL-deficient knee, thereby facilitating the return to sports. ${ }^{6,7}$

A systematic review and meta-analysis regarding return to sports following ACL reconstruction with more than 7,000
Copyright @ 2019 by Thieme Revinter Publicações Ltda, Rio de Janeiro, Brazil
License terms

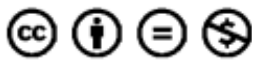


patients demonstrated that $81 \%$ of them resumed playing some form of sport after surgery, $65 \%$ resumed their previous level of sports activities, and 55\% returned to competitive sports. $^{8}$

Given the variability in what is demanded of the knee in the different sports, the outcomes after ACL reconstruction may vary. Patients appear to be more likely to return to activities such as bicycling and jogging after ACL reconstruction than to sports that are bruising and require pivoting, such as soccer and football. ${ }^{9}$

Despite ACL tear being a common and potentially serious soccer injury, there are relatively few studies on the outcomes, especially regarding the return to the same level of performance after ACL reconstruction in these athletes. ${ }^{10-14}$ Data on this would give orthopedic surgeons the ability to inform patients about what they should expect after surgery in terms of performance level, considering the return to the preinjury levels as the main indicator of success in ACL reconstruction.

The aim of the study is to evaluate the return to play in amateur soccer league players after ACL reconstruction, and to analyze the reasons why some of them have not returned.

\section{Methods}

The present study is a case series in which the surgical protocols of patients with ACL reconstruction surgeries performed in a sports medicine clinic between July $1^{\text {st }}$, 2013 , to June $30^{\text {th }}, 2014$, were included. Only the charts of amateur soccer league players who played once or twice a week (Tegner 9$)^{15}$ were selected. The exclusion criteria were: patients younger than 18 and older than 40 years of age; patients of the female gender; those who underwent revision ACL surgery or multiligament surgery; those who were professional (Tegner 10) or occasional (Tegner 7) soccer players; patients who mainly played a sport other than soccer; and those not possible to follow up.

The follow-up time was calculated as the number of months between surgery and the telephone survey.

For each surgical protocol, age, surgical technique, additional meniscal and/or chondral surgery, and type of graft were recorded.

The telephone survey was conducted by the main author. The current status of return to team playing (yes/no) was recorded. Those who did not return to play were asked what kind of sport they were currently playing (occasional soccer, another sport, or if they now led a sedentary lifestyle), and the main reason for not returning to play (fear of reinjury, knee symptoms, lack of confidence in their knee, family or job commitments, not being eligible to participate in competitive sports).

The Fisher exact test and the Mann-Whitney U test were used to calculate the differences between the group who returned to team playing and the one who did not.

\section{Results}

Over a 1-year period, a total of 238 patients underwent ACL reconstruction. From this group, 61 (25.6\%) met the inclusion

\section{Table 1}

\begin{tabular}{|l|l|}
\hline Excluded & 177 (74.3\%) \\
\hline Age $<18$ and $>40$ years & 25 \\
\hline Female gender & 10 \\
\hline Revision anterior cruciate ligament surgery & 23 \\
\hline Multiligament surgery & 10 \\
\hline Professional soccer players & 6 \\
\hline Occasional soccer players & 23 \\
\hline Main practice of another sport & 57 \\
\hline Not possible to follow up & 23 \\
\hline
\end{tabular}

criteria, and 177 (74,3\%) did not, and they were excluded (-Table 1). The mean follow-up time was of $22.4 \pm 3.4$ months. The mean age at the time of the surgery was of 29.7 years (standard deviation [SD]: 5.5 years; range: $20-40$ years).

All of the patients had an arthroscopically-assisted reconstruction of the ACL. In $85 \%$ cases, the surgical technique performed was transtibial, and in $15 \%$ it was medial portal. A total of $44(72.1 \%)$ patients were submitted to a concomitant surgery (-Table 2). Double semitendinosus-gracilis autografts were used in 50 surgeries, and bone-patellar-bone autografts were used in 11 of them.

At the final follow-up, 30 (49.1\%) patients were playing in an amateur soccer team. Out of those who did not return to team playing, 19 (61.2\%) were playing soccer occasionally, 11 (35.4\%) were playing other sports, and 1 (3.2\%) developed a sedentary lifestyle.

The main reason for not returning to play were: fear of reinjury in $26 \%$; knee symptoms in $26 \%$; lack of confidence in the knee in $23 \%$; family or job commitments in $23 \%$; and not being eligible to participate in competitive sports in $2 \%$.

There were only significant differences regarding age between the group who returned to team playing and the one who did not (-Table 3 ).

\section{Discussion}

Our study is the first to exclusively describe the return to play in amateur soccer league players after ACL reconstruction. It

\section{Table 2}

\begin{tabular}{|l|l|l|}
\hline Additional surgery & 44 & $\mathbf{7 2 . 1 \%}$ \\
\hline Medial meniscectomy & 7 & $11.4 \%$ \\
\hline Lateral meniscectomy & 34 & $55.7 \%$ \\
\hline Medial meniscal repair & 9 & $14.7 \%$ \\
\hline Lateral meniscal repair & 0 & $0 \%$ \\
\hline Microfracture of the trochlea/patella & 1 & $1.6 \%$ \\
\hline Microfracture of the medial femoral condyle & 0 & $0 \%$ \\
\hline Microfracture of the lateral femoral condyle & 1 & $1.6 \%$ \\
\hline
\end{tabular}


Table 3

\begin{tabular}{|l|l|l|l|}
\hline & \multicolumn{2}{l|}{$\begin{array}{l}\text { Return to amateur } \\
\text { soccer league }\end{array}$} & \\
\hline & $(+)$ & $(-)$ & p-value \\
\hline Age (years) & $28.1(20-39)$ & $\begin{array}{l}31.1 \\
(23-40)\end{array}$ & 0.04 \\
\hline $\begin{array}{l}\text { Time from surgery } \\
\text { (months) }\end{array}$ & $22.5(17-28)$ & $\begin{array}{l}22.3 \\
(18-28)\end{array}$ & 0.91 \\
\hline Surgical technique (n) & & $27 / 4$ & 0.73 \\
\hline $\begin{array}{l}\text { Transtibial/Medial } \\
\text { portal }\end{array}$ & $25 / 5$ & $26 / 5$ & 0.74 \\
\hline Type of autograft (n) & & $24 / 6$ & \\
\hline $\begin{array}{l}\text { Hamstrings/ } \\
\text { Bone-patellar-bone }\end{array}$ & & $22 / 9$ & 1 \\
\hline $\begin{array}{l}\text { Additional meniscal } \\
\text { and/or chondral } \\
\text { surgery (n) }\end{array}$ & $22 / 8$ & \\
\hline \begin{tabular}{l} 
Yes/No \\
\hline
\end{tabular}
\end{tabular}

has shown that only half of the amateur soccer league players return to play after an average of two years after surgery.

Our results are similar to those of a large cohort study ${ }^{16}$ with diverse competitive athletes that showed that 2 years after ACL reconstruction surgery only $60 \%$ of the participants had returned to their preinjury level of performance.

In another study with athletes who practice physically demanding sports, after an average time of 43 months from surgery to follow-up, only $42 \%$ of them resumed their previous performance levels or reached higher levels. ${ }^{17}$

Brophy et $\mathrm{al}^{10}$ analyzed the factors influencing return-toplay in soccer players with different levels of performance, and they reported that out of all patients who underwent ACL reconstruction, only $35 \%$ were still playing the sport at the 7 year follow-up. Of those still playing, only $46 \%$ were still playing at the same or at a higher level than before the injury. They concluded that younger and male soccer athletes are more likely to return to play after ACL reconstruction.

Our results in percentage of return to team playing were higher than those reported in these previous studies, probably due to the shorter follow-up time, and because our series consisted exclusively of physically demanding soccer players (Tegner 9), who are highly motivated to return to competition.

It is relevant to distinguish the performance level when analyzing the return-to-sport, because most professional and elite players are able to return to play at the same level as before the injury. This is probably because this group of patients presents major differences in caretaking compared with amateur players, considering diagnostic evaluation, time to surgery, and postoperative rehabilitation, as well as high financial incentives. ${ }^{18}$

One study ${ }^{14}$ presented the outcomes of a homogenous group of male professional soccer players who underwent ACL reconstruction; the authors reported that $95 \%$ and $62 \%$ of them returned to professional levels of performance at 1 year and 4 years respectively.
Another study ${ }^{13}$ with professional soccer players after ACL reconstruction, revealed that only $2 / 3$ of the players were still playing at the highest level 3 years later.

Some reports on ACL reconstruction in soccer players include patients with different sports performance levels. One study ${ }^{10}$ reported that after an average of 4 years after ACL surgery, $68 \%$ of the patients were still active soccer players. Analyzing this group by sport performance level, $37 \%$ played soccer at international or at the highest national level previous to injury.

The ability of the patients to return to sports after ACL reconstruction is influenced by various factors, which include postoperative knee function, social reasons and psychological state. One study prospectively ${ }^{19}$ analyzed the effects of various subjective scoring systems on return-tosports after ACL reconstruction, and found no significant differences between athletes who did and did not return to sports.

Multiple studies have reported that fear of reinjury, rather than clinical findings of instability or pain, is the single greatest reason for failure to return to sports. ${ }^{8,9,20}$ When analyzing fear of reinjury as a reason not to return to the preinjury performance level, our results were similar to those reported in a previous study, ${ }^{21}$ which describes that it is the main factor for not returning to play in $24 \%$ of the athletes who underwent ACL surgery.

The principal limitation of our study was the small sample size, which limited the scope of the data analysis. Another limitation was the lack of registration of the time period between ACL injury and surgery, and the volume and nature of rehabilitation pre- and postsurgery. Both factors could influence the return to sports to the same preinjury level.

One strength of our study was that it specifically evaluated, in amateur soccer players, the rate of return to the same level of performance as before the ACL injury. A return to the preinjury performance level was thought to represent the most robust assessment of a successful return-to-sports outcome. Previous studies did not specify whether the participants who returned to competitive sports returned to their preinjury level of performance or even to the same sport they used to play before the injury. ${ }^{14}$ As a result, these studies possibly overestimated the return-to-sports rate.

\section{Conclusion}

After an average of two years of ACL reconstruction, only half of the amateur soccer league players return to team playing.

Conflicts of Interest

The authors have none to disclose.

\section{References}

1 FIFA. (2007). Big Count 2006: Statistical Summary Report, FIFA Communications Division. Available at: http://fifa.com/mm/document/fifafacts/bcoffsurv/bigcount.statspackage_7024.pdf. Accessed 20 June 2018 
2 Rishiraj N, Taunton JE, Lloyd-Smith R, Woollard R, Regan W, Clement DB. The potential role of prophylactic/functional knee bracing in preventing knee ligament injury. Sports Med 2009;39 (11):937-960

3 Fridén T, Zätterström R, Lindstrand A, Moritz U. Anterior-cruciateinsufficient knees treated with physiotherapy. A three-year follow-up study of patients with late diagnosis. Clin Orthop Relat Res $1991 ;(263): 190-199$

4 Tegner Y, Lysholm J, Gillquist J, Oberg B. Two-year follow-up of conservative treatment of knee ligament injuries. Acta Orthop Scand 1984;55(02):176-180

5 Webb JM, Corry IS, Clingeleffer AJ, Pinczewski LA. Endoscopic reconstruction for isolated anterior cruciate ligament rupture. J Bone Joint Surg Br 1998;80(02):288-294

6 Cole BJ, Ernlund LS, Fu FH. Soft tissue problems of the knee. In: Baratz ME, Watson AD, Imbriglia JE, eds. Orthopaedic Surgery: The Essentials. New York: Thieme Medical Publishers, Inc.; 1999: 551-560

7 Starman JS, Ferretti M, Järvelä T, Buoncristiani A, Fu FH. Anatomy and biomechanics of the anterior cruciate ligament. In: Prodromos CC, ed. The Anterior Cruciate Ligament: Reconstruction and Basic Science. Philadelphia: Elsevier; 2008:3-11

8 Ardern CL, Taylor NF, Feller JA, Webster KE. Fifty-five per cent return to competitive sport following anterior cruciate ligament reconstruction surgery: an updated systematic review and metaanalysis including aspects of physical functioning and contextual factors. Br J Sports Med 2014;48(21):1543-1552

9 Warner SJ, Smith MV, Wright RW, Matava MJ, Brophy RH. Sportspecific outcomes after anterior cruciate ligament reconstruction. Arthroscopy 2011;27(08):1129-1134

10 Brophy RH, Schmitz L, Wright RW, et al. Return to play and future ACL injury risk after ACL reconstruction in soccer athletes from the Multicenter Orthopaedic Outcomes Network (MOON) group. Am J Sports Med 2012;40(11):2517-2522

11 Söderman K, Pietilä T, Alfredson H, Werner S. Anterior cruciate ligament injuries in young females playing soccer at senior levels. Scand J Med Sci Sports 2002;12(02):65-68
12 von Porat A, Roos EM, Roos H. High prevalence of osteoarthritis 14 years after an anterior cruciate ligament tear in male soccer players: a study of radiographic and patient relevant outcomes. Ann Rheum Dis 2004;63(03):269-273

13 Waldén M, Hägglund M, Magnusson H, Ekstrand J. ACL injuries in men's professional football: a 15 -year prospective study on time trends and return-to-play rates reveals only $65 \%$ of players still play at the top level 3 years after ACL rupture. Br J Sports Med 2016;50(12):744-750

14 Zaffagnini S, Grassi A, Marcheggiani Muccioli GM, et al. Return to sport after anterior cruciate ligament reconstruction in professional soccer players. Knee 2014;21(03):731-735

15 Tegner Y, Lysholm J. Rating systems in the evaluation of knee ligament injuries. Clin Orthop Relat Res 1985;(198):43-49

16 Ardern CL, Taylor NF, Feller JA, Whitehead TS, Webster KE. Sports participation 2 years after anterior cruciate ligament reconstruction in athletes who had not returned to sport at 1 year: a prospective follow-up of physical function and psychological factors in 122 athletes. Am J Sports Med 2015;43(04):848-856

17 Smith FW, Rosenlund EA, Aune AK, MacLean JA, Hillis SW. Subjective functional assessments and the return to competitive sport after anterior cruciate ligament reconstruction. $\mathrm{Br} \mathrm{J}$ Sports Med 2004;38(03):279-284

18 Ekstrand J. A 94\% return to elite level football after ACL surgery: a proof of possibilities with optimal caretaking or a sign of knee abuse? Knee Surg Sports Traumatol Arthrosc 2011;19(01):1-2

19 Gobbi A, Francisco R. Factors affecting return to sports after anterior cruciate ligament reconstruction with patellar tendon and hamstring graft: a prospective clinical investigation. Knee Surg Sports Traumatol Arthrosc 2006;14(10):1021-1028

20 Lee DY, Karim SA, Chang HC. Return to sports after anterior cruciate ligament reconstruction - a review of patients with minimum 5year follow-up. Ann Acad Med Singapore 2008;37(04):273-278

21 Kvist J, Ek A, Sporrstedt K, Good L. Fear of re-injury: a hindrance for returning to sports after anterior cruciate ligament reconstruction. Knee Surg Sports Traumatol Arthrosc 2005;13(05): 393-397 